\title{
Sonographic assessment of vessel invasion by cervical masses in dogs
}

[Avaliação ultrassonográfica da invasão vascular por massas cervicais em cães]

\author{
C.F. Carvalho, C.N. Ruivo, C.M. Simão, F.C. Viani
}

Escola de Medicina Veterinária - Universidade Cruzeiro do Sul - São Paulo, SP

\begin{abstract}
Tumor invasion of the vessels displays both therapeutic and prognostic implications and represents a challenge for head and neck surgeons. Although previous research has shown that ultrasound can detect such invasions, accurate sonographic parameters to do so have not yet been established. We sought to determine sonographic criteria which are able to characterize these invasions. A high-resolution transducer was used to perform ultrasound examinations of 15 patients selected from a group with inconclusive radiography and computed tomography diagnosis. We found that encasement of the vessel, tumor immobility or fixation in the vessel wall, and narrowing and/or deformity of the lumen were the best criteria. Indeed, when loss of hyperechoic interface of the vessel wall was used as a single criterion it generated false positive results. This study shows that a combination of parameters can be used to provide the best sensitivity and specificity values to produce conclusive diagnosis of vessel invasion by tumors in the cervical region.
\end{abstract}

Keywords: dog, tumors, ultrasonography, vessel invasion, carotid artery

\section{RESUMO}

Determinaram-se critérios ultrassonográficos capazes de caracterizar a invasão vascular por tumores em cães. Utilizaram-se transdutores de alta resolução para os exames ultrassonográficos realizados em 15 pacientes, selecionados de um grupo submetido previamente à radiografia e tomografia computadorizada, com resultados inconclusivos. Os melhores critérios encontrados foram: encarceramento do vaso, imobilidade do tumor ou aderência na parede vascular e estreitamento ou deformidade luminal. A perda de definição da interface hiperecoica da parede vascular quando foi usada como critério isolado produziu resultados falso positivos. O estudo demonstrou que uma combinação de parâmetros pode ser usada para aumentar a sensibilidade e especificidade diagnóstica, produzindo diagnósticos mais conclusivos e precisos pra definir a invasão vascular por tumores na região cervical ventral.

Palavras-chave: cão, tumor, ultrassonografia, invasão vascular, artéria carótida

\section{INTRODUCTION}

Tumor invasion of the carotid artery displays both therapeutic and prognostic implications. In some services it represents a real challenge to surgical resection, given the high risk of intraoperative death (Gooding et al., 1989; Gooding, 1993). In addition, a significant rise in morbidity is observed, including the formation of cervical abscesses, carotid rupture, and fistulas, besides brain, lung, and cardiac complications
(Langman et al., 1989; Fife et al., 2003; Slensky et al., 2003; Wisner et al., 1994).

The sonographic and tomographic evaluation of vessel invasion has been described (Langman et al., 1989; Zaragosa et al., 1993; Wisner et al., 1994; Zwingenberger and Wisner, 2008). However, the accuracy of each method remains controversial. Indeed, despite previous research on cervical vessel invasion through ultrasound, the most accurate sonographic parameters have not yet been established.

Recebido em 21 de junho de 2011

Aceito em 8 de fevereiro de 2012

E-mail: cibelefcarvalho@terra.com.br 
The objective of this study was to evaluate previously proposed criteria for cervical carotid artery and internal jugular invasion through ultrasound (US) in order to set the most accurate parameters for cervical vessel sonography in dogs. The study also correlated the three best sonographic parameters simultaneously, furthering the understanding about vessel invasion detection.

\section{MATERIAL AND METHODS}

A prospect study was made between January 2009 and January 2011 with fifteen patients selected from a group that was initially evaluated by computed tomography (CT) and conventional radiography, where the initial clinical suspicion was not clarified. The patients evaluated through US were suspected of having cervical tumors. They were elected to undergo tumor removal which was carried out with concomitant surgical observations regarding the vessel invasion (carotid and jugular) and sampling for histological correlations. The selected patients consisted of six males $(40 \%)$ and nine females $(60 \%)$, aged between 5 and 16 with mean age of 10 years.

All ultrasonographic examinations were performed by only one sonographer, using highdefinition equipment (model MyLab40, Esaote, Italy). High-resolution linear transducer was set to $15-18 \mathrm{MHz}$. B-mode, color and pulsed Doppler ultrasound studies were carried out. The analysis involved sagittal, transversal, and oblique sections of cervical carotids (internal, external, and common) and the jugular vein.

The criteria evaluated through B-mode US were: 1) loss of bright hyperechogenic layer in the contact area with tumor on the vessel wall; 2) reduction of vessel caliber and lumen deformity; 3) vascular encasement based on contact area between tumor and vessel up to $180^{\circ}$ (thrombosis and/or tumor protrusion into the lumen); 4) immobility evaluating tumor adherence to the vessels characterized by dynamic maneuvers, obtained with transducer in the suspected area (transversal section) waiting for swallowing and doing a light pressure with the transducer over the region.

Excised tumors were removed through surgery and samples were analyzed and categorized by histological criteria. Visualization of vessel invasion was performed during surgery and was considered gold standard. The histological diagnosis obtained was: 11 cases of thyroid carcinoma, 1 case of salivary duct adenocarcinoma, 1 case of chemodectoma and 2 cases of lymphoma.

Cross-tabulation analysis was used to assess sensitivity, specificity, positive predictive values, and negative predictive values. Cohen's Kappa coefficient and Spearman rank correlation coefficient were also calculated. A $P$ value below 0.05 was considered to indicate a significant difference.

\section{RESULTS}

It is sought to establish sonographic criteria values that could help in the detection of vessel invasion by malignant tumors (Table 1 ). In order to define the best parameters, we evaluated sensitivity and specificity for each criterion (Table 2).

These data revealed that the three best parameters were reduction of caliber vessel or lumen deformity, encasement, and immobility. Together these three parameters resulted in $100 \%$ sensitivity, 93\% specificity, positive predictive value of $85 \%$, and negative predictive value of $100 \%$. Accuracy obtained was $94 \%$ with good calculated concordance (kappa $=0.70)$. There were no false negative cases. Thus, taking the three parameters together, there was improved sensitivity, specificity, and positive and negative predictive values obtained.

In this ultrasound diagnoses study using the criteria elected, the only sign of vascular invasion four patients had was the loss of hyperechogenic band criteria (Figure 1). The result was that these were false positive cases. It is worth noting that fixation status of the carotids to the tumor, researched through dynamic maneuvers, contributed to the reduction in the number of false positive cases, since its absence excluded the hypothesis of invasion, even in cases of apparent tumor encasing (Figure 2). An aneurism in common carotid artery (Figure 3) and a pseudoaneurism in jugular vein probably secondary to the presence of the adjacent tumor were also observed. 
Sonographic assessment...

Table 1. Distribution of sonographic and histology findings in 15 dogs with cervical masses

\begin{tabular}{|c|c|c|c|c|c|c|c|c|}
\hline Animal & Breed & Sex & $\begin{array}{c}\text { Age } \\
\text { (years) }\end{array}$ & Histology & $\begin{array}{l}\text { Loss of } \\
\text { bright } \\
\text { ecogenic } \\
\text { layer }\end{array}$ & $\begin{array}{l}\text { Lumen } \\
\text { deformity }\end{array}$ & $\begin{array}{c}\text { Vascular } \\
\text { encasement }\end{array}$ & $\begin{array}{l}\text { Immobility } \\
\text { and/or } \\
\text { tumor } \\
\text { adherence }\end{array}$ \\
\hline 1 & Poodle & M & 9 & $\begin{array}{l}\text { Salivary gland duct } \\
\text { adenocarcinoma }\end{array}$ & yes & yes & yes & yes \\
\hline 2 & Lhasa Apso & M & 11 & $\begin{array}{l}\text { Thyroid } \\
\text { carcinoma/jugular } \\
\text { pseudoaneurism }\end{array}$ & yes & yes & no & no \\
\hline 3 & Pekinese & $\mathrm{F}$ & 9 & Thyroid carcinoma & yes & yes & yes & yes \\
\hline 4 & Mongrel & $\mathrm{F}$ & 13 & $\begin{array}{l}\text { Thyroid scamous cells } \\
\text { carcinoma }\end{array}$ & yes & yes & yes & yes \\
\hline 5 & Fox terrier & M & 9 & $\begin{array}{l}\text { Thyroid carcinoma } \\
\text { and } \\
\text { limphonodomegaly }\end{array}$ & yes & no & no & no \\
\hline 6 & Labrador & $\mathrm{F}$ & 5 & Thyroid carcinoma & yes & no & no & no \\
\hline 7 & Mongrel & $\mathrm{F}$ & 10 & $\begin{array}{l}\text { Thyroid carcinoma } \\
\text { and } \\
\text { limphonodomegaly }\end{array}$ & yes & no & yes & no \\
\hline 8 & Rottweiller & M & 12 & Thyroid carcinoma & no & no & no & no \\
\hline 9 & Fox terrier & M & 13 & Thyroid carcinoma & no & no & no & no \\
\hline 10 & Mongrel & $\mathrm{F}$ & 15 & Lymphoma & no & no & no & no \\
\hline 11 & Boxer & $\mathrm{F}$ & 9 & Chemodectoma & yes & yes & yes & yes \\
\hline 12 & Cocker & M & 8 & Thyroid carcinoma & no & no & no & no \\
\hline 13 & Dachshund & $\mathrm{F}$ & 7 & Lymphoma & yes & no & no & no \\
\hline 14 & Lhasa Apso & $\mathrm{F}$ & 16 & Thyroid carcinoma & yes & no & no & no \\
\hline 15 & Mongrel & $\mathrm{F}$ & 11 & $\begin{array}{l}\text { Thyroid carcinoma } \\
\text { and tracheal metastasis }\end{array}$ & yes & yes & yes & yes \\
\hline
\end{tabular}

Table 2. Statistical results of sensitivity, specificity, positive predictive value (PPV) and negative predictive value NPV of each sonographic criterion evaluated in $15 \mathrm{dogs}$

\begin{tabular}{|c|c|c|c|c|c|c|}
\hline US & Sensitivity & Specificity & PPV & NPV & Accuracy & $P$-value \\
\hline Criteria & $(\%)$ & $(\%)$ & $(\%)$ & $(\%)$ & $(\%)$ & \\
\hline Loss of hyperechogenic band & 40.0 & 80.0 & 36.4 & 100.0 & 53.3 & 0.6004 \\
\hline $\begin{array}{l}\text { Reduction of vessel caliber and/or } \\
\text { lumen deformity }\end{array}$ & 100.0 & 90.0 & 83.3 & 100.0 & 93.3 & 0.002 \\
\hline Encasement & 100.0 & 90.0 & 83.3 & 100.0 & 93.3 & 0.002 \\
\hline Immobility & 100.0 & 100.0 & 100.0 & 100.0 & 100.0 & 0.0003 \\
\hline
\end{tabular}

\section{DISCUSSION}

Carotid artery invasion represents a challenge for head and neck surgeons both in terms of diagnosis and treatment. Clinical examination is extremely difficult, especially in patients with huge masses and lymph nodes fixed to the muscle.

US is a non-invasive method that is easily accessible and offers an accurate carotid evaluation, with higher resolution than CT scanning or even magnetic resonance imaging (MRI) in the cervical region (Langman et al., 1989). To set the value of sonographic criteria for the detection of vessel invasion by tumors, four parameters were evaluated in patients with doubtful vascular invasion diagnosis from either physical, radiographic and/or CT examinations. Although the parameters chosen have been evaluated separately in other studies, in this study they were all examined simultaneously. 


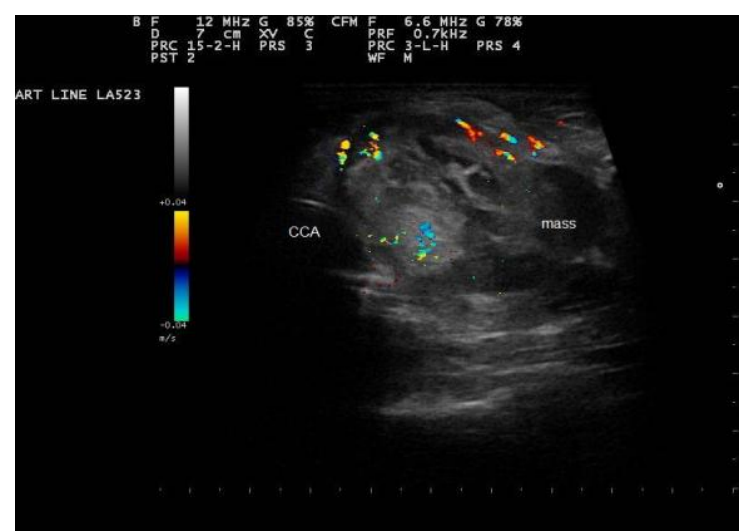

Figure 1. Dog. Common carotid artery (CCA) with loss of bright hyperechogenic layer in the contact area with neoplasic mass of the vessel wall. Color Doppler mapping shows mass vascularization.
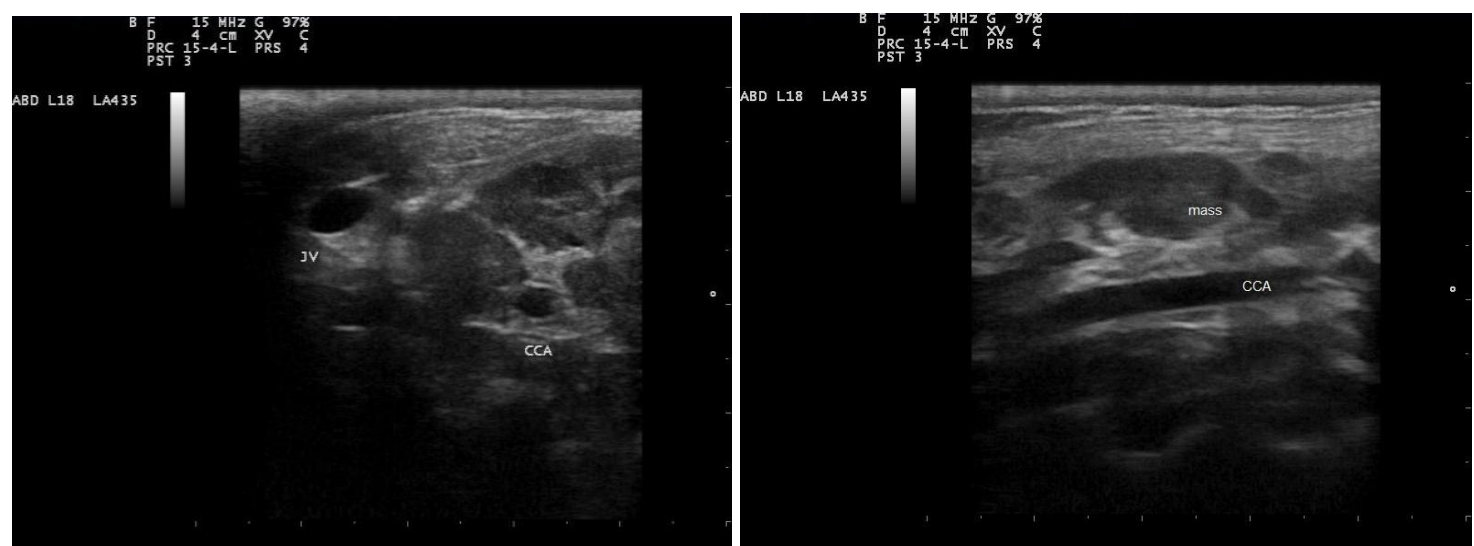

Figure 2. Dog. A) Transversal section of thyroid mass with no adherence to the vessels (characterized by dynamic maneuvers), jugular vein (JV) and common carotid artery (CCA) with apparent tumor encasement. B) Sagittal plane showing that there is no vessel invasion.

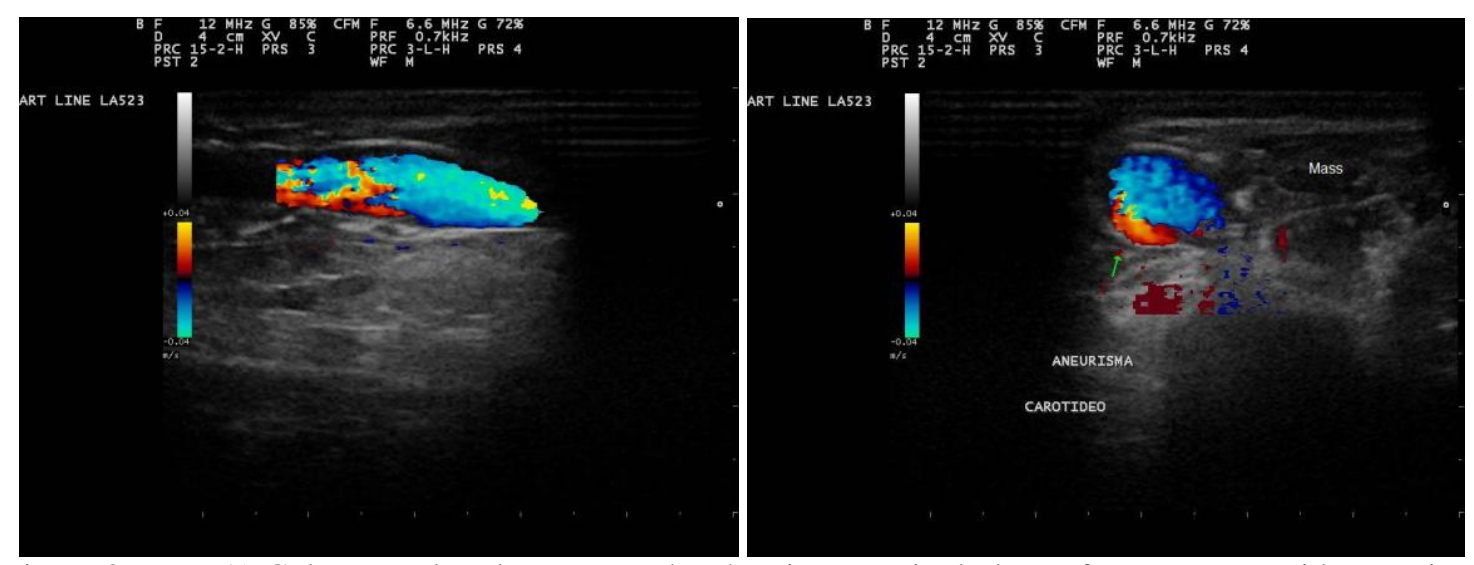

Figure 3. Dog. A) Color Doppler ultrasonography showing a sagittal plane of common carotid artery in a dog with segmental dilation and luminal flow with aliasing artifact. B) Transversal plane of color Doppler ultrasonography demonstrating flow within the aneurysm and the typical "yin-yang" appearance, corresponding to the inflow and outflow regions of the aneurysm. It also shows the intimal flap separated into two lumina and neoplasic mass adherences. 
Studying human patients with inconclusive physical examination or CT scan signs of vascular invasion, a study (Langman et al., 1989) set criteria for CT, MRI, and US for carotid involvement. In the US case, the criterion used was the loss of the bright hyperechogenic layer along the artery wall. Their histopathologic correlation proved US to have a superior performance than CT and physical examination in vascular invasion evaluation. In accordance with what is reported in literature (Langman et al., 1989; Slensky et al., 2003; Wisner et al., 1994; Zwingenberger and Wisner, 2008) it was found that preservation of the hyperechogenic band decreases the possibility of vessel invasion, resulting in a true negative value $(100 \%)$, with high specificity rate $(80 \%)$. However, the sensitivity value of this signal when considered alone is low (40\%).

Bright hyperechoic layering was considered in literature as the main direct sign of vascular invasion (Gooding et al., 1989; Gooding, 1993; Zwingenberger and Wisner, 2008). Through a prospective study, they tried to establish criteria that ruled out the possibility of vascular invasion, accepting a high number of false positives to increase sensitivity. Taking data from the present study together with previously published data, it is possible to conclude that loss of the hyperechogenic band is not an accurate enough criterion when used alone. However, these results showed that it is a useful parameter to compose a panel for vessel invasion evaluation because when it was used in conjunction with other criteria, accuracy was improved.

In the present study, research, intraoperative and histological data confirmed that US correctly identified all dogs with carotid artery encasement. It was also found that US results were higher for CT, similar to the conclusion reported before in literature (Langman et al., 1989). Once again, encasement alone cannot be considered an accurate enough criterion, but we showed it is a helpful component in composing a panel with other parameters to evaluate vessel invasion.

Another criterion evaluated in the present study was the reduction of vessel caliber and/or lumen deformity (Figure 4). Used as a single criterion, it produced a significant increase in the number of false positives, thus reducing the accuracy of US, but, as will be discussed further on, analysis of this criterion in conjunction with other criteria improved the sensitivity of the method.

To help exclude vessel infiltration, dynamic maneuvers (waiting for swallowing and light pressure with the transducer) performed during the examination were used to assess tumor immobility in relation to the artery wall in all patients. This parameter proved to be very useful because when mobility was present we could exclude the possibility of vascular invasion by adjacent neoplasia. However, when mobility was not found the diagnosis was inconclusive. Tumor immobility can be present in patients without vessel invasion caused by inflammatory process in the adjacent tissues induced by the tumor itself. Thus, these data indicated that although tumor fixation to vessel (immobility) does not confirm vascular invasion, its absence excludes the possibility of such diagnosis, even in cases where vessel encasement by neoplasia is detected. Therefore, tumor immobility is a good criterion to be used in combination with others listed herein

US is limited in that it does not allow the assessment of the relation between the tumor and the carotid artery above the base of the skull, thus making the use of both CT and MRI paramount. However, the findings presented here provide consistent data indicating that US may have good diagnosis accuracy for cervical vessel tumor invasion if a multicriteria panel is analyzed simultaneously. Indeed, when it was used, the combination of the three best sonographic parameters obtained improved sensitivity, specificity, and positive and negative predictive values.

The use of US with a multicriteria analysis may be helpful to establish a more conclusive diagnosis of vessel invasion when physical examination or CT scanning has produced suspicious or inconclusive results. It was established that vessel caliber reduction and/or lumen deformity, encasement and tumor immobility may constitute the best signs when analyzed in conjunction (Figure 5). This study indicated which combination of parameters could be used with the best sensitivity and specificity values to assess tumor artery invasion and produced a conclusive diagnosis. Further studies are necessary to evaluate whether there is a difference in vessel invasion determined by tumor characteristics. 


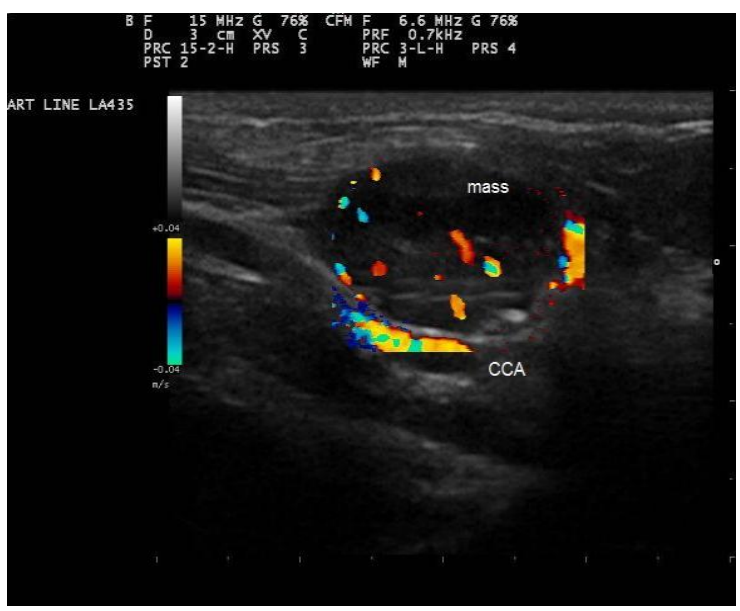

Figure 4. Dog. Sagittal plane of color Doppler mapping of ventral neck region showing a well vascularized tumor and mass effect leading to a reduction of the vessel caliber of the common carotid artery (CCA) in a dog.

\section{REFERENCES}

FIFE, W.; MATTOON, J.S.; DROST, W.T. et al. Imaging features of a presumed carotid body tumor in a dog. Vet. Radiol. Ultrasound., v.44, p.322-325, 2003.

GOODING, G.A.W.; LANGMAN, A.W.; DILLON, W.P.; KAPLAN, M.J. Malignant Carotid Artery Invasion: Sonographic Detection. Radiology, v.171, p.435-438, 1989.

GOODING, G.A. Malignant carotid invasion: sonographic diagnosis. ORL J Otorhinolaryngol. Relat. Spec., v.55, p.263-272, 1993.

LANGMAN, A.W.; KAPLAN, M.J.; DILLON, W.P.; GOODING, G.A. Radiologic assessment of tumor and the carotid artery correlation of magnetic resonance imaging, ultrasound, and computed tomography with surgical findings. Head Neck, v.11, p.443-449, 1989.

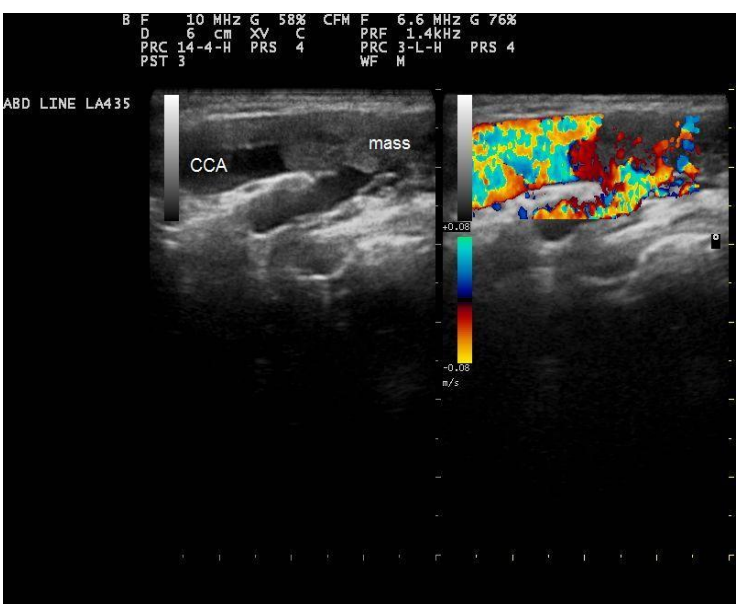

Figure 5. Dog. Color Doppler sonography of a huge echoic mass into the lumen of the common carotid artery (CCA) near the bifurcation of the internal carotid artery - chemodectoma in an eight year old Boxer.

SLENSKY, K.A.; VOLK, S.W.; SCHWARZ, T. et al. Acute severe hemorrhage secondary to arterial invasion in a dog with thyroid carcinoma. J. Am. Vet. Assoc., v.223, p.649-653, 2003.

WISNER, E.R.; NYLAND, T.G.; MATTOON, J.S. Ultrasonographic examination of cervical masses in the dog and cat. Vet. Radiol. Ultrasound., v.35, p.310-315, 1994.

ZARAGOZA, L.; SENDRA, F.; SOLANO, J. et al. Ultrasonography is more effective than computed tomography in excluding invasion of the carotid wall by cervical lynphadenopathies. Eur. J. Radiol., v.17, p.191-194, 1993.

ZWINGENBERGER, A.; WISNER, E.N. In: Penninck, D.; D'Anjou, M.A. Atlas of Small Animal Ultrasonography. 1.ed. Iowa: Blackwell Publishing, 2008. p.91-117. 